\title{
Microalbuminuria as an Earliest Predictor of Diabetic Nephropathy
}

\author{
*Dr.SarikaD.Katore ${ }^{1}$, Dr.Prasanna M. Fating ${ }^{2}$ \\ ${ }^{1}$ Department of Biochemistry, JNMC Sawangi (meghe), Wardha, Maharashtra \\ ${ }^{2}$ Department of Biochemistry, Divisional railway Hospital Nagpur, Maharashtra
}

\begin{abstract}
Diabetes mellitus is major health problem worldwidwe,characterised by persistent hyperglycaemia due to defect in insulin secretion, insulin action or both. Diabetic nephropathy is one of the major complications of diabetes mellitus.The present study aimed to asses urine microalbumin in patients of diabetes mellitus and diabetic nephropathy. This cross sectional study was undertaken in the Department of Biochemistry GMC and super speciality hospital Nagpur, Maharashtra.Urine microalbumin was assessed in diabetes mellitus $(n=50)$, diabetic nephropathy $(n=50)$ and healthy individuals $(n=50)$. Mean of biochemical parameter were compared by performing repeated measures one way ANOVA(F-test) and Post hoc multiple comparison of mean of three groups by Bonferroni t-test.Urinemicroalbuminwas significantly higher in diabetes mellitus with diabetic nephropathy and diabetes mellitus without diabetic nephropathy patients as compared to control $(p<0.001)$.There was slightly higher urine microalbumin observed in diabetes mellitus without diabetic nephropathy as compared to control. The difference was statistically non significant ( $p>0.05$ ).Microalbuminuria is risk factor for diabetic nephropathy.so regular screening for microalbuminuria should be done to delay complication of diabetes mellitus
\end{abstract}

Keywords: Diabetes mellitus, Diabetic nephropathy, Urinemicroalbumin, microalbuminuria

\section{Iintroduction}

The term diabetes mellitus describes a metabolic disorder of multiple etiologies characterized by chronic hyperglycemia with disturbances of carbohydrate, fat and protein metabolism resulting from defect in insulin secretion, insulin action or both.[1 ]Diabetes leads to various complications such as coronary artery disease, peripheral vascular disease, stroke, neuropathy, diabetic nephropathy, retinopathy and diabetic foot. The global prevalence of diabetes mellitus is expected to increase from 4\% in 1995 to 5.4\% by the year 2025.[2] Diabetic nephropathy is one of the major complications of diabetes mellitus.

The classical definition of diabetic nephropathy is a progressive rise in urine albumin excretion, increasing blood pressure, leading to declining glomerular filtration and eventually end stage renal disease (ESRD). [3]Diabetes is the most common cause of kidney failure. Chronic kidney disease (CKD) and kidney failure can occur in uncontrolled as well as in controlled diabetes. ESRD is the final stage of chronic kidney disease. [4 ]The prevalence of diabetic nephropathy in India was less (8.9\% in Vellore, 5.5\% in Chennai) as compared to Asian Indians (22.3\%) in the UK.[5] The prevalence of diabetic nephropathy in chronic renal failure patients in India was $30.3 \%$ followed by chronic interstitial nephritis (23\%) and chronic glomerulonephritis (17.7\%).[6]The impairment in kidney function over the time has been associated with initial glomerular filtration rate, initial urinary albumin excretion rate (UAE), hyperglycaemia and old age.[7]Microalbuminuria is a marker for diabetic nephropathy and cardiovascular disease in patients with both type I and type II diabetes mellitus.[8-11] The urine dipstick is a relatively insensitive marker for proteinuria, not becoming positive until protein excretion exceeds 300 to $500 \mathrm{mg} /$ day so using a specific assay for albumin is a more sensitive technique.

One of the earliest markers of diabetic nephropathy is the presence of small amount of the protein albumin in the urine. This is called MAU or microalbuminuria (urinary albumin excretion of 30-300 mg/24 hours).The aim of the present study was to study the urine microalbumin in patients of diabetic nephropathy.

\section{Materials And Method:}

The present study has been carried out in Govt. medical college and hospital, Nagpur, India Jaunary 2011 to July 2012. The study protocol was approved by the Institutional Ethical Committee. Informed written consent was obtained from all the study subjects enrolled in the study. Study sample was consisted of total of 150 individuals; 50 diagnosed cases of diabetes mellitus with diabetic nephropathy irrespective of type I and type II diabetes (Cases) in the age group of 30-70 years and 50 patients of diabetes mellitus of either sex, admitted in kidney unit of medicine department in the institute and Nehrology department in GMC and super speciality hospital, Nagpur and 50 age and sex matched controls were also selected for study. 


\subsection{Inclusion criteria}

Age $>30$ yrs and $<70$ yrs

Registered cases of diabetic mellitus with and without diabetic nephropathy irrespective of type I and type II diabetes mellitus.

\subsection{Exclusion criteria}

Age $<30$ yrs and $>70 y r s$

Patients with gestational diabetes

Individual with urinary tract infection

Patients with provisional diabetes or impaired glucose tolerance

Patients having any mental disorder

Individuals having any past medical history of various vascular complications before the diagnosis of diabetes mellitus such as ischemic heart disease, cerebral and peripheral vascular diseases, congestive heart failure and renal failure

Those who did not consent to participate in the study.

\subsection{Specimen collection and preservation:}

\subsubsection{Urine sample:}

$2 \mathrm{ml}$ urine sample was collected in plain bulb. Microalbumin in urine was estimated on the same day.

\subsubsection{Blood sample}

$2 \mathrm{ml}$ venous blood was collected in fluroid bulb for fasting blood glucose level after an overnight fast (i.e. after 12 hours) and 1and half hour after meal for postprandial blood glucose level

\subsection{Laboratory Analysis}

Blood glucose level was estimated by glucose oxidase peroxidase (GOD-POD) method.Urinemicroalbumin was estimated by Pyragallol Red End Point method[12]

\subsection{Statistical analysis:}

Statistical data was recorded on Microsoft Excel programme and analysed by using statistical software STATA version 10.0

All continuous variables were presented as mean \pm standard deviation.

Categorical variables are expressed as percentages.

Urine microalbumin in three group were compared by performing repeated measures one way ANOVA (Ftest).

Post hoc multiple comparison of mean of three groups by Bonferroni t-test.

\section{Results}

Table 1 shows patients of diabetic nephropathy with mean age $56.02 \pm 6.92$ years consisted of 34 males with and 16 females and patients of diabetes mellitus with with mean age 50.44 years consisted of 33 males and 17 females whereas mean age of controls $50.08 \pm 8.42$ years consisted of and 17 female .We found diabetes mellitus with diabetic nephropathy patients were of older age group as compared to diabetes mellitus without diabetic nephropathy and control group.

The number of males in cases of diabetes mellitus without diabetic nephropathy and in control group was 33 and in diabetes mellitus with diabetic nephropathy were 34 . The number of females in cases of diabetes mellitus without diabetic nephropathy and in control was 17 and in diabetes mellitus with diabetic nephropathy were 16 . We found higher number of males in diabetes mellitus with diabetic nephropathy as compared to female

Table 1: Age and Gender Distribution of study group

\begin{tabular}{|l|l|l|l|}
\hline & Controls & $\begin{array}{l}\text { Diabetic } \\
\text { nephropathy } \\
\text { patients }\end{array}$ & $\begin{array}{l}\text { Diabetes } \\
\text { mellitus } \\
\text { patient }\end{array}$ \\
\hline Age & $50.08 \pm 8.42$ & $56.02 .08 \pm 6.92$ & $50.44 \pm 9.4$ \\
\hline Male & 33 & 34 & 33 \\
\hline Female & 17 & 18 & 17 \\
\hline
\end{tabular}


Figure 1: Agewise distribution in cases and controls

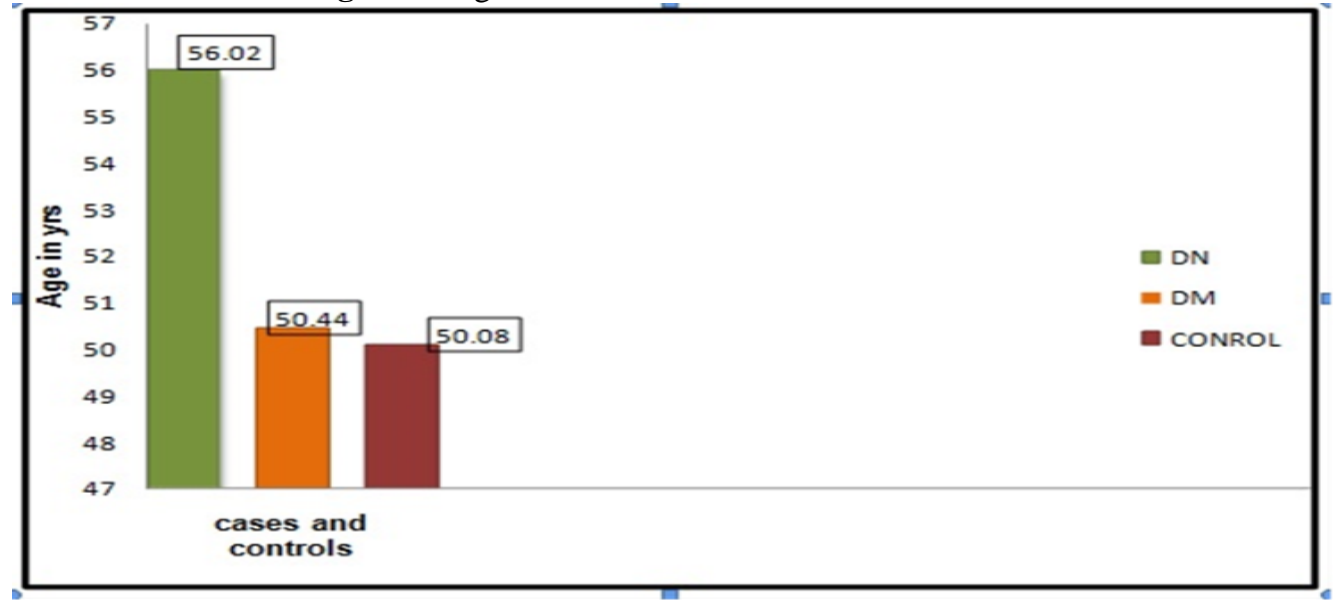

Table 2 shows urine microalbumin in cases of diabetes mellitus with diabetic nephropathy and diabetes mellitus without diabetic nephropathy group and control. There was higher level of urine microalbumin, fasting and postmeal plasma glucose observed in diabetes mellitus with diabetic nephropathy group as compared to diabetes mellitus without diabetic nephropathy and control group and the difference was statistically highly significant $(\mathrm{p}<0.001)$. There was slightly higher urine microalbumin observed in diabetes mellitus without diabetic nephropathy as compared to control. The difference was statistically non significant $(\mathrm{p}>0.05)$.

Table 2: Urinemicroalbumin in diabetes mellitus with diabetic nephropathy ,diabetes mellitus without diabetic nephropathy and in control

\begin{tabular}{|l|l|l|l|l|}
\hline Variables & $\begin{array}{l}\text { Diabetesmelltuswith diabetic } \\
\text { nephropathy }(\mathrm{n}=50)\end{array}$ & $\begin{array}{l}\text { Diabetes melltus } \\
\text { without diabetic nephropathy } \\
(\mathrm{n}=50)(\mathrm{Mean}+\mathrm{SD})\end{array}$ & $\begin{array}{l}\text { Controls } \\
(\mathrm{n}=50) \\
(\mathrm{Mean}+\mathrm{SD})\end{array}$ \\
\hline Plasma glucose F (mg\%) & $137.18+9.32^{\mathrm{a},}$ & $111.02+21.60^{\mathrm{b}}$ & $92.56+10.84$ \\
\hline Plasma glucose PM (mg\%) & $181.55+30.79 \quad{ }^{\mathrm{a}, \mathrm{b}}$ & $136.26+18^{\mathrm{b}}$ & $116+11.06$ \\
\hline $\begin{array}{l}\text { Urine microalbumin } \\
(\mathrm{mg} / 24 \mathrm{hr})\end{array}$ & $87.19+37.53^{\mathrm{a}, \mathrm{b}}$ & $11.82+6.44^{\mathrm{c}}$ & $11.24+6.37$ \\
\hline
\end{tabular}

$\mathrm{a}=\mathrm{p}<0.001$ when compared with $\mathrm{DM} ; \mathrm{b}<0.001$ when compared with controls $; \mathrm{c}=\mathrm{p}>0.05$ when compared with control

SD: Standard Deviation;DM: Diabetes mellitus

Figure 2: urine microalbumin in diabetes mellitus with diabetic nephropathy, diabetes mellitus without diabetic nephropathy and in control group

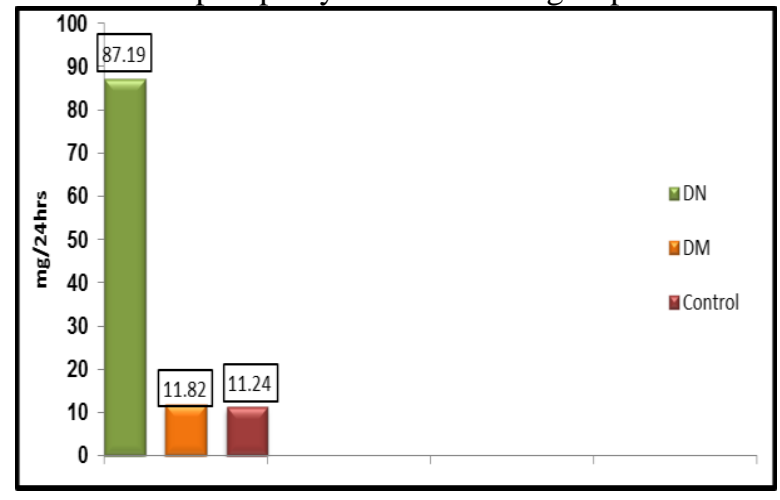

\section{Discussion}

Microalbuminuria is a marker for diabetic nephropathy and cardiovascular disease in patients with diabetes mellitus. Microalbuminuria is the earliest predictor of renal damage in diabetic nephropathy. Microalbuminuria is the increased passage of albumin through the glomerular filtration barrier. The Initial mechanism for development of microalbuminuria is glomerular endothelial dysfunction due to damage to its 
glycocalyx layer. [13] This glycocalyx covers glomerular endothelial cell luminal surface. The glycocalyx layer is composed of glycoproteins and proteoglycans with adsorbed plasma proteins. Heparan sulphate proteoglycans (HSPGs) are responsible for the negative charge of glycocalyx. Reactive oxygen species (ROS) disrupt the glycocalyx. Removal of the glycocalyx increases vascular protein permeability through glomerular basement membrane and therefore increases albumin excretion rate.[14,15] Chowta NK et al [16] observed that there was higher number of male diabetic nephropathy patients as compared to female. Microalbuminuria patients were of older age group. Finding of this study also resembles with our study. The findings of our study are similar to those observed by Naveen et al [17]who found higher mean microalbuminuria in uncontrolled diabetes mellitus patients when compared with controlled diabetes mellitus. They also observed that the levels of HbA1c and microalbuminuria increases with duration of the disease. Our study findings are in accordance with those of Jha et al [18] who found the mean value of fasting blood glucose in microalbuminuric patients was higher as compared to normoalbuminuria

\section{Conclusion}

Patients with both type I and type II diabetes are at risk of diabetic nephropathy.Diabetic nephropathy develops in 20-30\% of type I and type II diabetes mellitus patients.Microalbuminuria is a earliest marker for renal damage in diabetes mellitus. So detection of microalbuminuria is an indication for screening for possible vascular diseases

\section{Acknowledgment}

I would like to thank staff of Biochemistry department GMC , Nagpur for their support throughout the study.

\section{References}

[1] Definition, Diagnosis and Classification of Diabetes Mellitus and its Complications WHO/NCD/NCS/99.2 Original: English Distr : General.

[2] King H, Aubert RE, Herman WH. Global burden of diabetes, 1995-2025: prevalence, numerical estimates, and projections. Diabetes Care 1998; 21: 1414-1431.

[3] Update in Diabetic Nephropathy. Enyioma N Obineche and Abdu Adem.Int J Diabetes \& Metabolism.2005; 13 : 1-9 7.

[4] United States Renal Data System. USRDS 2007 Annual Data Report. Bethesda. National Institute of Diabetes and Digestive and Kidney Diseases, National Institutes of Health U.S. Department of Health and Human Services, 2007

[5] Ramachandran A. Socio-economic burden of diabetes in India. J Assoc Physicians India. 2007 July; 55 : 9-12. 9.

[6] Viswanathan V, Snehalatha C, Ramachandran A. Diabetic nephropathy strategy of management. Int. J. Diab. Dev Countries 2000; $20 ; 45$.

[7] SilveiroSP,Friedman R, gross JL. Glomerular Hyperfiltration in NIDDM patients without overt proteinuria . Diabetic care . 1993 Jan ; 16:115-119

[8] American diabetes association Nephropathy in diabetes.Diabetic care.2004 Jan; 27(1) :S79-S83.

[9] Gaede P, Tarnow L, Vedel P et al.Remission to normoalbuminuria during multifactorial treatment preserves kidney function in patients with type 2 diabetes and microalbuminuria. Nephrol Dial Transplant 2004 August 24;19:2784 -2788.

[10] Gerstein HC, Mann JF, Yi Q, Zinman B, Dinneen SF, Hoogwerf B et al. HOPE Study Investigators: Albuminuria and risk cardiovascular events, death, and heart failure in diabetic and nondiabetic individuals. JAMA. 2001 July 25;286(4 ):421-426.

[11] Garg JP, Bakris GL: Microalbuminuria: marker of vascular dysfunction, risk factor for cardiovascular disease. VascMed $2002 ; 7: 35-4387$

[12] Bradford MM. A Rapid and Sensitive Method for the Quantitation of Microgram Quantities of Protein Utilizing the Principle of Protein-Dye Binding.Bradford MM. Analytical Biochemistry 1976 Jan $29 ; 72: 248-254$.s

[13] Deckert T, Feldt-Rasmussen B, Borch-Johnsen K et al. Albuminuria reflects widespread vascular damage. The Steno hypothesis. Diabetologia.1989 april; 32(4):219-226. 129.

[14] Huxley VH, Williams DA. Role of a glycocalyx on coronary arteriole permeability to proteins: evidence from enzyme treatments. Am J Physiol Heart Circ Physiol.2000; 278:H1177-H1185.

[15] Rehm M, Zahler S, LotschM,Welsch U, ConzenP,Bernhard F et al .Endothelial glycocalyx as an additional barrier determining extravasation of $6 \%$ hydroxyethyl starch or 5\% albumin solutions in the coronary vascular bed. Anesthesiology.2004; 100:12111223.

[16] Chowta NK, Pant P, Chowta MK. Indian journal of nephrology. Microalbuminuria in diabetes mellitus: Association with age, sex, weight, and creatinine clearance .2009 July 10;19(2): 53-56

[17] Naveen P, Kannan N , Annam V et al. Evaluation of Glycatedhemoglobin and Microalbuminuria as early risk markers of Nephropathy in Type 2 Diabetes Mellitus. Int J Biol Med Res. 2012; 3(2): 1724-1726

[18] Jha P,DasBKL,Shresthas,Majhis,ChandraL,Sharma S et al. Glycaemic status,lipid profile and proteinuria in diabetic nephropthy.J Nepal Med Assoc 2010;49(178):143-6 IOSR Journal of Biotechnology and Biochemistry (IOSR-JBB) is UGC approved Journal with SI. No.
4033, Journal no. 44202 .

Dr.SarikaD .Katore. "Microalbuminuria as an Earliest Predictor of Diabetic Nephropathy." IOSR Journal of Biotechnology and Biochemistry (IOSR-JBB) 3.3 (2017): 69-72. 